\title{
Combined Endoscopic-Radiologic Minimally Invasive Rescue Technique for the Removal of a Migrated and Embedded Biliary Metal Stent
}

\author{
Pavlos Antypas ${ }^{1,2}$, Mario Corona ${ }^{3}$, Cristian Eugeniu Boru ${ }^{1^{*}}$, Chiara Eberspacher ${ }^{4}$, Domenico Mascagni ${ }^{4}$, \\ Fausto Fiocca ${ }^{2}$
}

Corresponding author:

Dr. Cristian E Boru

Division of General Surgery \&

Bariatric Center of Excellence-IFSO

EC, Department of Medico-Surgical

Sciences and Biotechnologies

Sapienza University of Rome

Via Franco Faggiana 1668

Latina 04100, Italy

Tel 003907736513374

Fax 003907736513333

E-mail: drcrisb@gmail.com

Received: 07.09.2021

Accepted: 16.11.2021

$\overline{\text { Copyright } \odot \text { Celsius Publishing House }}$ www.sgo-iasgo.com
'Division of General Surgery \& Bariatric Center of Excellence-IFSO EC,

Department of Medico-Surgical Sciences and Biotechnologies, Sapienza University of Rome, Italy ${ }^{2}$ Emergency Endoscopy Unit, Policlinico Umberto I, Sapienza University of Rome, Italy ${ }^{3}$ Department of Radiological Sciences, Oncology and Pathology, Vascular and Interventional Unit, Sapienza University of Rome, Italy ${ }^{4}$ Department of Surgical Sciences, Policlinico Umberto I, Sapienza University of Rome, Italy

\section{ABSTRACT}

Bile duct injuries represent a rare but potentially serious complication after laparoscopic cholecystectomy, that often need multidisciplinary therapeutic approaches. Additionally, post cholecystectomy clip migration into the biliary tree has been described, mainly because of local inflammatory processes. We present a case of a 65-year-old male with a bile duct injury and stricture after laparoscopic cholecystectomy treated endoscopically with sphincterotomy and stent positioning; initially with a plastic 10Fr stent and later with a totally covered metal stent. At the removal, the metal stent appeared proximally migrated and embedded with a surgical clip, the latter also migrated into the bile duct. The endoscopic retrieval of the stent was unsuccessful and thus a simultaneous right percutaneous transhepatic approach was adopted to liberate the stent and to facilitate the endoscopic procedure. The combined endoscopic-radiologic minimally-invasive approach seemed to be an effective and safe rescue technique, avoiding in this way complex surgical procedures.

Key words: bile duct, ERCP, injury, intraoperative complications, laparoscopic cholecystectomy

\section{INTRODUCTION}

A postoperative bile duct injury is a serious and potentially devastating complication that usually occurs after technical error associated with cholecystectomy. In the era of laparoscopic cholecystectomy, the incidence of major bile duct injuries has increased (from $0.4 \%$ to $0.6 \%$ ) (1). The therapeutic approaches include surgery and/or endoscopic techniques (Endoscopic Retrograde CholangioPancreatography/ERCP) such as sphincterotomy with stent positioning (2). More complicated injuries may require combined radiologic-endoscopic "rendez-vous" technique (3). Post cholecystectomy clip migration (PCCM) is a rare 
complication after laparoscopic cholecystectomy. Additionally, proximal migration is a late adverse event of biliary stenting that renders technically challenging their retrieval. We describe a combined endoscopicradiologic technique for the removal of a proximal migrated biliary metal stent that was also trapped and embedded with a surgical clip and suture; the last ones migrated into the common bile duct (CBD) after laparoscopic cholecystectomy.

\section{CASE REPORT}

A 65-year-old male underwent laparoscopic cholecystectomy for gallbladder stones with a surgical drainage tube placed for safety reasons. Four days later the patient presented fever, right upper abdominal quadrant pain and presence of bile into the drainage tube. The patient underwent ERCP that illustrated a type C1 bile duct injury [Hannover classification (4)] (fig. 1a). During the procedure, sphincterotomy was performed and a 10Fr plastic stent was placed (fig. 1b). Three months later, the stent was endoscopically removed, and the cholangiography showed a bile duct's stricture [type B1Hannover classification (4)] near a surgical clip, localized almost $1 \mathrm{~cm}$ below the hepatic confluence (fig. 1c). A totally covered metal stent $\left(\right.$ GORE $^{\circledR}$ VIABIL ${ }^{\circledR}$ Biliary Endoprosthesis, W.L. Gore \& Associates, Flagstaff, AZ, USA) was placed to treat the stricture (fig. 1d).

Nine months later an ERCP was performed for its removal but the distal edge was proximally migrated. Foreign body retrieval forceps, Dormia basket, balloon extractor and balloon dilation techniques were used unsuccessfully to remove the stent (fig. 2a). To avoid surgery, a percutaneous transhepatic approach was decided to liberate the stent and to facilitate the endoscopic procedure. Briefly, a radiologic controlled puncture of the sixth hepatic segment with a Chiba needle (22 gauge) was performed. Cholangiography was carried out to confirm the correct positioning and afterwards a 10Fr introducer was placed. A 0.035-inch hydrophilic guidewire (Terumo, Tokyo, Japan) was used to cannulate the $\mathrm{CBD}$, passing laterally to the metal stent and arriving at the duodenum. An $8 \mathrm{~mm}$ balloon dilator was used to liberate the embedded stent (fig. 2b). After several attempts the stent was removed endoscopically with a foreign body retrieval forceps, dragging both a trapped metal clip and a surgical suture (fig. 2c, fig. 3); the last one probably inserted in an attempt to correct the bile duct's defect during the surgical procedure. The consecutive control showed neither ulterior injuries nor strictures of the bile duct

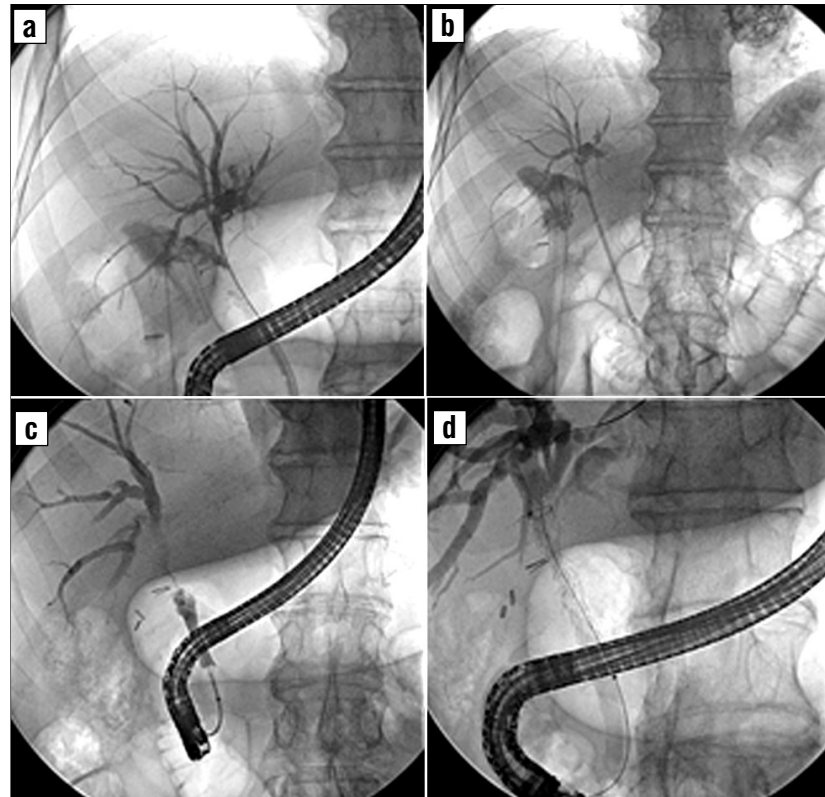

Figure 1 - (a) Type C1 bile duct injury (tangential bile duct lesions according to the Hannover classification (4); (b) 10Fr plastic stent placed for bile injury treatment; (c) Type B1 stenosis after plastic stent removal (biliary tract occlusion according to the Hannover classification (4); (d) Totally covered metal stent positioning for B1 stenosis treatment

(fig. 2d). A transhepatic drainage was placed for safety reasons and removed after 2 days without complications. The patient was dismissed in good general condition.

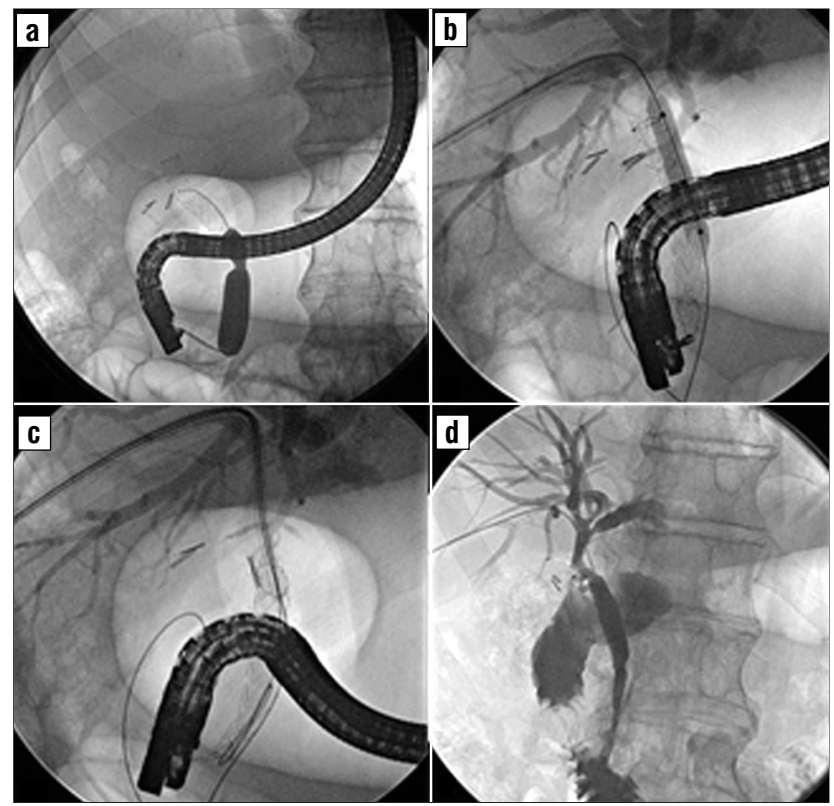

Figure 2 - (a) Endoscopic balloon dilation; (b) Transhepatic approach and balloon dilation; (c) Metal stent removal; (d) Final control before transhepatic drainage removal 


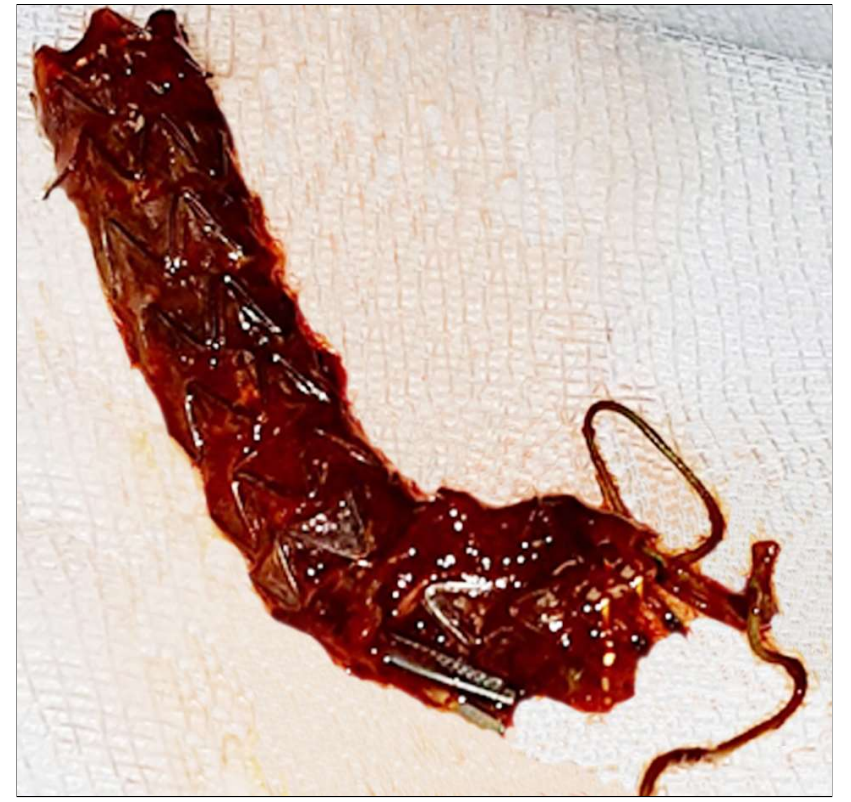

Figure 3 - Metal stent with embedded surgical clip and suture

\section{DISCUSSION}

Since its introduction, surgical hemostatic clips have been widely used and are generally considered as very safe. Migration of clips into the bile duct with stone formations is rare but well recognized $(5,6)$. The precise pathogenesis of PCCM is unidentified but probably involve complex sets of proceedings occurring simultaneously (6). The process involves the initial migrations of clip into the biliary tree and followed later by stone formations. Apart from migration into the biliary tree, PCCM may lead to other complications such as duodenal ulcer or clip embolism $(7,8)$. There are many factors that contribute to the migration process. These include inaccurate clip placements with subsequent bile duct injuries, local inflammatory mechanisms, bile leak and local infective processes. In fact, once a clip gets embedded within the bile duct wall, the process of clip migration will continue (9). The location of the stricture indicates the probable site of clip injury and migration. The number of clips used during the initial surgery is also an important factor and the use of more than four clips is associated with clip migration (9).

Usually, the removal of totally covered biliary metal stents is not considered such a demanding procedure (10). CBD or papilla stenosis, acute angulation of distal $\mathrm{CBD}$, presence of surgical clips or sutures and proximal migration of the stent may complicate the procedure (11). In these situations, advanced endoscopic techniques are necessary, such as the guide-wire technique into the stent lumen with balloon dilation and extraction $(12,13)$. Recently, cholangioscopy assisted procedures have been described with good results (14). However, cholangioscopy equipment is expensive and not always available. Additionally, most of the reports describe retrieval techniques for plastic stents and only a few data are available regarding the removal of proximally migrated metal stents.

In our case, the metal stent was not only proximally migrated but also embedded with a surgical clip and suture and therefore standard and advanced endoscopic removal techniques have failed. The combined endoscopic-radiologic minimally invasive approach seemed to be an effective and safe rescue technique, avoiding in this way complex surgical procedures.

\section{CONCLUSION}

Finally, we would suggest that in cases of complicated laparoscopic cholecystectomies with possible bile duct injuries, the use of clips should be limited as it may lead to further complications and if the surgeon is not experienced enough to perform biliary sutures, it would be safer to leave a drainage without further treatment. Then, the patient must be referred to a tertiary center where an adequate therapeutic approach will be applied.

\section{Conflict of interests}

Authors declare no conflict of interests for this article.

Funding information: nothing to declare

\section{Ethical Statement}

All procedures performed were in accordance with the ethical standards of the 1964 Helsinki Declaration and its later amendments.

\section{Author's contributions}

The contribution of each author, as defined by the ICMJE guidelines, is as follows: Pavlos Antypas: design of work, data acquisition, analysis, and interpretation; drafting and revision; final approval; accuracy and integrity; Mario Corona: data acquisition, analysis, and interpretation; drafting; final approval; accuracy and integrity; Cristian E Boru: data acquisition, analysis, and interpretation; drafting; final approval; accuracy and 
integrity; Chiara Eberspacher: data acquisition, analysis, and interpretation; drafting; final approval; accuracy and integrity; Domenico Mascagni: data acquisition, analysis, and interpretation; drafting; final approval; accuracy and integrity; Fausto Fiocca: design of work, data acquisition, analysis, and interpretation; revision; final approval; accuracy and integrity.

\section{REFERENCES}

1. Wu YV, Linehan DC. Bile duct injuries in the era of laparoscopic cholecystectomies. Surg Clin North Am. 2010;90(4):787-802.

2. Rauws EA, Gouma DJ. Endoscopic and surgical management of bile duct injury after laparoscopic cholecystectomy. Best Pract Res Clin Gastroenterol. 2004;18(5):829-46.

3. Fiocca F, Salvatori FM, Fanelli F, Bruni A, Ceci V, Corona M, et al. Complete transection of the main bile duct: minimally invasive treatment with an endoscopic-radiologic rendezvous. Gastrointest Endosc. 2011;74(6):1393-8.

4. Bektas H, Schrem H, Winny M, Klempnauer J. Surgical treatment and outcome of iatrogenic bile duct lesions after cholecystectomy and the impact of different clinical classification systems. $\mathrm{Br}$ J Surg. 2007:94(9):1119-27.

5. Onghena T, Vereecken L, Van den Dwey K, Van Loon C. Common bile duct foreign body: an unusual case. Surg Laparosc Endosc. 1992;2(1):8-10

6. Ghavidel A. Migration of clips after laparoscopic cholecystectomy; a case report and literature review. Middle East J Dig Dis.
2015;7(1): 45-9.

7. Matsuura T, Kanisawa Y, Sato T, Saito T, Hirata K. Migration of "endo-clips" into common bile-duct after laparoscopic cholecystectomy. Lancet. 1992 Aug 1;340(8814):306.

8. Ghazanfari K, Gollapudi PR, Konicek FJ, Olivera A Jr, Madayag M, Warner J. Surgical clip as a nidus for common bile duct stone formation and successful endoscopic therapy. Gastrointest Endosc. 1992;38(5):611-3.

9. Brutvan FM, Kampschroer BH, Parker HW. Vessel clip as a nidus for formation of common bile duct stone. Gastrointest Endosc. 1982 Aug;28(3):222-3.

10. Kasher JA, Corasanti JG, Tarnasky PR, McHenry L, Fogel E, Cunningham J. A multicenter analysis of safety and outcome of removal of a fully covered self-expandable metal stent during ERCP. Gastrointest Endosc. 2011;73(6):1292-7.

11. Dumonceau JM, Tringali A, Papanikolaou IS, Blero D, Mangiavillano B, Schmidt A, et al. Endoscopic biliary stenting: indications, choice of stents, and results: European Society of Gastrointestinal Endoscopy (ESGE) Clinical Guideline - Updated October 2017. Endoscopy. 2018;50(9):910-930.

12. Tarnasky PR, Cotton PB, Baillie J, Branch MS, Affronti J, Jowell $P$, et al. Proximal migration of biliary stents: attempted endoscopic retrieval in forty-one patients. Gastrointest Endosc. 1995;42(6):513-20.

13. Calcara C, Broglia L, Comi G, Balzarini M. Plastic Biliary Stent Migration During Multiple Stents Placement and Successful Endoscopic Removal Using Intra-Stent Balloon Inflation Technique: A Case Report and Literature Review. Am J Case Rep. 2016:17:65-9.

14. Al Lehibi A, Al Mtawa A, Almasoudi T, Al Ghamdi A, Al Otaibi N, Al Balkhi A. Removal of proximally migrated biliary stents by using single-operator cholangioscopy. VideoGIE. 2020;5(5):213-216. 